\title{
Barreiras invisíveis e rotas alternativas: uma análise sobre (i)mobilidade
}

\section{urbana e produção de subjetividades}

Invisible barriers and alternative routes: an analysis about urban (in)mobility and production

$$
\text { of subjectivities }
$$

Barreras invisibles y caminos alternativos: un análisis sobre (in)movilidad urbana y producción de subjetividades

\author{
Luísa Horn de Castro Silveira \\ Cristianne Maria Famer Rocha \\ Julio Celso Borello Vargas
}

Universidade Federal do Rio Grande do Sul (UFRGS), Porto Alegre, RS, Brasil

\begin{abstract}
Resumo
Promover a mobilidade urbana saudável nas grandes cidades é um desafio, em especial em regiões marcadas por desigualdades socioeconômicas, onde fatores físico-estruturais somamse a questões subjetivas (barreiras invisíveis) que inibem ou dificultam o deslocamento da população pelo território. O objetivo do estudo foi problematizar os modos pelos quais a mobilidade urbana é afetada por barreiras invisíveis em uma região da cidade de Porto Alegre. Para realizar essa investigação foi utilizado um método qualitativo de pesquisa-intervenção e a análise dos dados foi realizada a partir de algumas ferramentas teóricas de Michel Foucault. Os resultados encontrados permitem pensar que as barreiras invisíveis de mobilidade estão relacionadas aos modos de subjetivação existentes em contextos urbanos específicos, ligados às relações de poder engendradas na cidade contemporânea, às sensações de isolamento e exclusão, à atmosfera de medo e insegurança e aos processos de segregação (re)produzidos localmente.
\end{abstract}

Palavras-chave: Cidade; Mobilidade Urbana; Subjetividade; Saúde Urbana; Segregação Socioespacial.

\begin{abstract}
Promote healthy urban mobility in big cities is a challenge, especially in regions with socialeconomic inequities. Places where infrastructural factors add to subjective issues (invisible barriers) that inhibit or hinder people's journeys around the territory. The aim of the study was to investigate how urban mobility is affected by invisible barriers in a region of Porto Alegre city in the South of Brazil. A qualitative method of intervention research was used and
\end{abstract}


the analysis was produced using concepts of Michel Foucault. Findings permit to relate invisible mobility barriers with the existing modes of subjectivation in particular urban contexts. Those are connected to power relations engendered in contemporary urban life, to the feeling of exclusion and isolation, to the fear atmosphere and insecurity and to segregation processes (re)produced locally.

Keywords: Cities; Urban Mobility; Subjectivity; Urban Health; Socio-spatial Segregation.

\section{Resumen}

Promover la movilidad urbana saludable en las grandes ciudades es un desafío, especialmente en regiones marcadas por desigualdades socioeconómicas, donde factores físico-estructurales se suman a cuestiones subjetivas (barreras invisibles) que inhiben o dificultan el desplazamiento de la población por el territorio. El objetivo del estudio fue problematizar los modos por los que la movilidad urbana es afectada por barreras invisibles en una región de la ciudad de Porto Alegre (Brasil). Para realizar esta investigación se utilizó un método cualitativo de pesquisa-intervención y los análisis fueron elaborados a partir de algunos conceptos teóricos de Michel Foucault. Los resultados encontrados permiten pensar que las barreras invisibles de movilidad están relacionadas con los modos de subjetivación existentes en contextos urbanos específicos, vinculados a las relaciones de poder engendradas en la ciudad contemporánea, a los sentimientos de aislamiento y exclusión, a la atmósfera de miedo e inseguridad y a los procesos de segregación (re)producidos localmente.

Palabras clave: Ciudad; Movilidad Urbana; Subjetividad, Salud Urbana, Segregación Socioespacial.

\section{Introdução}

$\mathrm{O}$ presente artigo apresenta os resultados de uma pesquisa de Mestrado Acadêmico em Saúde Coletiva, realizada durante a execução do Projeto "Healthy Urban Mobility" - Mobilidade Urbana Saudável (HUM-MUS). O Projeto HUMMUS visava a entender o impacto da (i)mobilidade cotidiana na saúde e bemestar, comparando grupos sociais que vivem em diferentes cidades (HUM Project, 2016). Segundo a Organização Mundial da Saúde (OMS), o princípio da mobilidade urbana saudável é oferecer aos residentes a possibilidade de acessar suas necessidades diárias facilmente através de caminhadas, pedaladas ou transporte público (WHO, 2016). O desenho da cidade, portanto, deve ser planejado de modo a incentivar o transporte ativo, inserindo atividade física na rotina comum dos cidadãos. $\mathrm{O}$ conceito de mobilidade urbana saudável se relaciona com os debates sobre sustentabilidade na gestão das cidades, os quais defendem que fatores ambientais, econômicos e sociais devem ser considerados no planejamento urbano, incluindo a questão do transporte. Promovendo práticas sustentáveis, como a diminuição do uso de veículos motorizados 
individuais, espera-se que a saúde da população seja positivamente afetada cidades caminháveis e cicláveis não só incentivam uma rotina mais ativa, mas também alteram a dinâmica do uso do espaço, aumentando as chances de fortalecimento das redes comunitárias e a sensação de bem-estar (Cohen, Boniface \& Watkins, 2014).

Mobilidade urbana saudável, no entanto, não se resume apenas à mobilidade ativa. Sabe-se que muitas pessoas não utilizam automóveis para se deslocar por razões econômicas e de acesso. Nem todo deslocamento ativo pode ser automaticamente considerado saudável, especialmente tendo em vista os contrastes de infraestrutura oferecidos em diferentes localidades, definidos principalmente por disparidades econômicas que se materializam no espaço construído. A mobilidade urbana afeta amplamente a saúde da população em variados aspectos e é considerada tema central na discussão do impacto do desenvolvimento urbano na qualidade de vida da população, que tem particular efeito nos bairros periféricos, pois sistemas de mobilidade ineficientes refletem na desigualdade socioespacial (Carvalho, 2016).

Mesmo que a cidade seja um local de livre circulação para seus habitantes, a utilização dos espaços nem sempre ocorre de maneira democrática. $\mathrm{O}$ debate sobre o direito à cidade está entremeado pelo entendimento da lógica da localização dos recursos no espaço urbano, sejam eles a moradia, as oportunidades de emprego, os serviços e os equipamentos urbanos. Nessa concepção, a garantia de mobilidade e a luta pela utilização do espaço urbano de forma equânime pelos seus habitantes é essencial para a efetivação de outros direitos como educação, saúde e lazer.

Dentre as muitas abordagens possíveis para estudar o tema da mobilidade em diferentes contextos urbanos, o estudo apresentado nesse artigo tem como objeto de investigação as barreiras "invisíveis" que dificultam a mobilidade da população urbana, especialmente em bairros que são sócioespacialmente segregados, ou seja, colocados à margem dos recursos e oportunidades oferecidos pela cidade. Em muitos casos, as regiões segregadas localizam-se a uma grande distância geográfica do centro, o que por si só já repercute em um problema de mobilidade. Porém, outras vezes, um bairro ou comunidade se localiza próximo às regiões centrais da cidade, mas o que existe é "uma distância sociológica a um centro, sendo este definido pela diversidade e pela densidade das relações sociais, pela intensidade da vida cívica, pelo acesso à 
informação, pela aglomeração de recursos culturais, políticos, econômicos, etc" (Domingues, 1994, p. 7). É especialmente esse contraste econômico, social e simbólico entre localidades vizinhas que instigou a realização dessa pesquisa, entendendo que existem separações sutis dentro de espaços geográficos próximos, que também podem ser compreendidas como barreiras de mobilidade urbana.

Por barreiras "invisíveis", entendese aquilo que vai além da estrutura física da cidade. A utilização do espaço urbano de forma justa depende tanto de fatores concretos, como uma boa oferta de transporte coletivo e manutenção de vias públicas (que podem apresentar obstáculos, como buracos, alagamentos, vegetação sem poda etc.), quanto de fatores culturais, psicológicos, sociais e econômicos (Feltran, 2016a). Em geral, essas barreiras - visíveis e invisíveis atuam juntas para reforçar a segregação social existente nas grandes cidades.

Além do menor acesso a recursos, regiões segregadas são tipicamente de baixa renda e podem ou não ter características de assentamento informal. Para o Instituto Brasileiro de Geografia e Estatística (IBGE, 2018), o que popularmente se conhece por diferentes nomes, dependendo da região do Brasil favela, comunidade, vila, grotão, mocambo, entre outros - chama-se "aglomerado subnormal": um conjunto de unidades habitacionais caracterizadas por ausência de título de propriedade, irregularidade das vias de circulação e do tamanho e forma dos lotes e, comumente, carência de serviços públicos essenciais (coleta de lixo, rede de esgoto, iluminação pública etc.). Na cidade de Porto Alegre, local da investigação aqui relatada, é comum vermos assentamentos informais mesclados com áreas de habitação formal, especialmente em bairros de nível econômico mais baixo. Nessa lógica, quando se fala de acesso a direitos, as favelas seriam a forma de habitação urbana mais marginalizada nas cidades, o que faz pensar em diferentes níveis e procedimentos possíveis de segregação. A palavra "favela" não é a mais utilizada no vocabulário do porto-alegrense, que normalmente prefere o termo "vila". Dependendo do contexto em que se fala, "vila" serve para designar, tanto as grandes áreas de baixa renda de um modo geral (não necessariamente com moradias precárias), quanto aos assentamentos informais, ou favelas propriamente ditas.

Essa pesquisa foi realizada em uma região com essas características: próxima ao centro, mas considerada de baixa renda e com disparidades econômicas e urbanísticas internas - alguns locais com infraestrutura mais completa, outros com característica de favela -, diferenças essas 
que, como veremos, também produzem disputas de espaço e barreiras simbólicas de mobilidade. Enfatizam-se aqui os dispositivos criados pelos próprios habitantes (da região estudada e da cidade como um todo) para a manutenção dessas barreiras. Michel Foucault (2008a) nos alertava que a exclusão de certos grupos sociais é um jogo que se atualiza constantemente, mudando os sentidos e as formas de acordo com a cultura e o momento histórico. Pode-se pensar, então, que a aplicação de políticas e práticas recomendadas para se alcançar uma mobilidade urbana saudável pode ser dificultada por certos mecanismos e forças de ordem cultural e subjetiva, alimentados por ações e situações cotidianas. Dessa forma, faz-se necessário analisar e compreender esses processos para aprimorar soluções possíveis para impasses de mobilidade urbana em nível local.

Com o intuito de adotar, portanto, uma visão que possibilitasse ver além dos problemas concretos e que questionasse o instituído e naturalizado, tomamos algumas ferramentas de Michel Foucault para essa análise. Para Foucault, como discorre Roberto Machado no prefácio de "Microfísica do Poder" (Foucault, 1979), as práticas e relações de poder estão disseminadas por toda a estrutura social e são uma "forma de organização do espaço
[...] uma técnica de distribuição dos indivíduos através da inserção de corpos em um espaço individualizado, classificatório" (p. XVII). Essas práticas, ainda de acordo com a explicação do autor, não precisam de um espaço fechado para se realizar, estão presentes no campo social e, consequentemente, no cotidiano da pólis. Entendemos que as relações de poder e seus dispositivos são conceitos intrinsecamente ligados a algumas das barreiras invisíveis que dificultam a utilização equânime do espaço urbano.

Adota-se nessa discussão a premissa de que o espaço físico não é apenas contexto externo à constituição dos sujeitos (Cardoso Filho, 2016), pelo contrário: a produção de subjetividade ocorre em agenciamento com o espaço ao redor. A cidade e a relação que se estabelece com ela são elementos constituintes da subjetividade. Como espaço existencial, a cidade oferece múltiplas experiências sensoriais, cognitivas e emocionais que se alteram ao longo da história e a depender das circunstâncias e particularidades de cada local (Justo \& Heguedush, 2019). Com isso em mente, para além da saúde e bemestar em termos observáveis ou mensuráveis, interessa pensar como a forma como nos relacionamos com $\mathrm{o}$ espaço ajuda a desenhar nossa vida 
psíquica, os modos de ser no mundo. Barreiras de mobilidade, assim pensadas, são muros que impedem a expansão da existência dos sujeitos, despotencializando-os.

O estudo realizado, objetivamente, se propôs a pensar a seguinte questão: como a mobilidade urbana é afetada por barreiras invisíveis na região estudada? $\mathrm{Ou}$, usando o referencial adotado, que regimes de verdade dificultam ou regulam a livre (e saudável) circulação das pessoas pelo território urbano? Quais os regimes de verdade que operam(os) nas cidades, impedindo os habitantes de circular livremente? Assim, o objetivo desse estudo é problematizar os modos pelos quais a mobilidade urbana é afetada por barreiras invisíveis em uma região sócioespacialmente segregada de Porto Alegre.

\section{Métodos}

Essa é uma pesquisa de cunho qualitativo. Pretende-se aprofundar nas especificidades de uma dada situação e provocar reflexões sobre o tema estudado. A ênfase da pesquisa qualitativa é sobre os processos que não podem ser medidos em termos de quantidade, investigando o modo como a experiência social é criada e adquire significado (Denzin, Lincoln \& Netz, 2006). O método utilizado caracteriza-se por uma pesquisaintervenção, visto que a pesquisadora principal esteve envolvida ativamente com o campo de pesquisa durante o período do estudo (como será melhor explicitado a seguir) e a relação com o campo é também objeto de análise. Entende-se que a compreensão da realidade ocorre também a partir do próprio observador e a interferência da pesquisa no campo é intrínseca ao processo de investigação (Ferigato \& Carvalho, 2011). Nesse sentido, toma-se a análise de implicação como ferramenta para pensar o campo estudado: durante a aproximação com a realidade observada, procurou-se estar permanentemente atenta ao impacto que as cenas vividas exerciam sobre a pesquisadora, levando em consideração sua própria história e o lugar que ocupa social e politicamente em relação ao universo de estudo (Paulon, 2005).

A produção de informações para análise foi realizada em duas etapas: uma primeira de reconhecimento do território, lançando mão do diário de campo como ferramenta de produção de material para análise e, depois, entrevistas com moradores da região estudada. A etapa do diário de campo ocorreu de novembro de 2016 a maio de 2017, durante a coleta de dados realizada pelo Projeto HUM-MUS sobre as condições de mobilidade e saúde dos moradores de uma região de Porto Alegre, na qual a autora principal participou como supervisora das atividades 
de campo. O trabalho de supervisão de campo consistia em fazer visitas semanais ao bairro estudado (que depois dos primeiros meses passaram a ser quinzenais) para reuniões de monitoramento com os entrevistadores contratados pelo Projeto HUM-MUS alguns deles, moradores locais. Essas reuniões ocorriam em um espaço cedido por um centro comunitário e eram o momento em que os entrevistadores (moradores ou não) contavam suas experiências, circulando pelo bairro e interagindo com as pessoas entrevistadas, ouvindo diariamente relatos sobre viver e se deslocar naquele local. Também foram realizadas duas saídas de campo antes do início da coleta, para o mapeamento das vizinhanças incluídas na amostra e apresentação da pesquisa a lideranças comunitárias e alguns comerciantes da região - encontros nos quais o assunto "mobilidade urbana" virava tópico de conversas informais. Essas experiências produziram interessantes diálogos, registrados pela pesquisadora em diário de campo, resultando na primeira parte da produção de dados.

A seguir, foram realizadas quatro entrevistas com moradores da região, com o intuito de aprofundar compreensões sobre as vivências de mobilidade no bairro. A escolha das pessoas entrevistadas teve como principal critério um longo período vivendo na Região - todas elas residem ali há pelo menos 15 anos e três delas tinham importantes histórias de atuação comunitária. $\mathrm{O}$ formato de entrevista utilizado se aproxima da definição de entrevista narrativa, que consiste em pedir que os participantes contem suas histórias ou relatos sobre determinado assunto, em vez de responderem perguntas (Flick, 2009). Os participantes foram solicitados a contar suas histórias de vida, dando ênfase à forma como se locomoveram ao longo dos anos ou décadas e o que motivou suas escolhas de mobilidade. Foi dada especial atenção aos seus relatos de circulação dentro e fora do bairro onde moram, suas impressões, sensações e relações com o espaço e pessoas ao redor.

A preocupação em valorizar os participantes da pesquisa e ser fiel às suas histórias e relatos é o principal posicionamento ético assumido nesse estudo. A pesquisa interventiva requer situar-se em relação ao outro, ancorando a produção de conhecimento nos efeitos de reconhecimento e estranhamento das diferenças em relação a esse outro (Andrade, Morato \& Schmidt, 2007). As entrevistas foram realizadas mediante assinatura de Termo de Consentimento Livre e Esclarecido (TCLE). A pesquisa foi avaliada pelo Comitê de Ética em 
Pesquisa da Secretaria Municipal de Saúde (CEP/SMS) de Porto Alegre, sob o Certificado de Apresentação para Apreciação Ética (CAAE) número 58214416.9.3001.5338.

Os pseudônimos utilizados nesse texto foram escolhidos pelos próprios participantes entrevistados. São eles: Cazuza, 47 anos, líder comunitário; Joana, 53 anos, que trabalhou como faxineira desde os 14 anos, mas atualmente é dona de casa; Anita, 48 anos, educadora e estudante de graduação em uma universidade privada localizada na área do estudo; e Mogli, 22 anos, estudante de graduação em uma universidade privada na região metropolitana da cidade e estagiário. Todos eles usam modos ativos para se locomover: caminhadas combinadas com uso de transporte público para trechos mais longos e, no caso de Mogli, a bicicleta é utilizada como meio de transporte principal. A adoção do transporte ativo, apesar da estrutura precária oferecida pelo bairro, faz com que os quatro entrevistados estejam de acordo com a lógica de saúde e sustentabilidade preconizada, mas, para além disso, ao nos aprofundarmos em suas histórias, é possível mostrar como o enfrentamento cotidiano de obstáculos menos palpáveis amplia noções de saúde e bem-estar relacionadas com a forma de circular pelos espaços de vida. Para melhor compreensão dos resultados e análises, as falas dos entrevistados estão identificadas pelos seus pseudônimos e as anotações do diário de campo estão identificadas pela sigla "D.C".

As informações obtidas a partir do diário de campo e das entrevistas foram agrupadas por aproximação de significados, constituindo quatro unidades de análise, que serão discutidas a seguir: 1) Abismos e distâncias; 2) Atmosfera de medo e zonas proibidas; 3) Muros grossos e paredes finas; 4) Pontes e rotas alternativas.

\section{Resultados e Discussão}

\section{Abismos e Distâncias}

Um ponto em comum entre os entrevistados de mais idade, e que representa também a realidade de muitos moradores de longa data no bairro estudado, é que a comunidade se constitui como principal cenário de vida, pano de fundo de suas histórias pessoais, de modo que suas trajetórias parecem se misturar com a urbanização do território. Chamou atenção, em especial na entrevista de Joana, o pouco envolvimento com a cidade ampliada, a ponto de não conseguir resgatar muito bem, em suas memórias, experiências em qualquer outro local de Porto Alegre. Sua vida realmente acontece ali dentro da região, como se essa fosse algo à parte em relação ao todo da cidade. 
Nota-se que morar nesse bairro é condição acompanhada, muitas vezes, de um sentimento de isolamento. Nas falas de todos entrevistados, assim como nas conversas com outros moradores, foi possível extrair algo relacionado a essa temática. Uma das entrevistadas descreve a mobilidade na região da seguinte forma: "aparentemente tão perto de tudo e tão ruim [em termos] de mobilidade [...] a gente se sente ilhada" (Anita). Apesar de a região estar em uma localização bastante privilegiada (próxima ao Centro, ao Lago Guaíba e a outros pontos de referência da cidade), parece difícil deslocar-se dali para esses locais. Mogli, ao falar sobre o transporte público no local, conta que a oferta de ônibus no seu bairro permite que se vá até o centro, mas se há o desejo de ir a outras partes da cidade, é necessário sempre tomar dois ônibus, fazendo com que a distância, que seria curta, pareça maior para quem opta por esse tipo de transporte. Ou seja, há um "abismo" que separa a região estudada do resto da cidade, tanto pela forma como as rotas de transporte público estão organizadas, quanto pela sensação de afastamento do entorno.

Em anotações no diário de campo, é relatado um diálogo entre moradores sobre as sensações de circular em um bairro de classe média próximo, comentando as diferenças de acesso às residências: enquanto no bairro de classe média um visitante precisa interagir com interfones, seguranças e portões automáticos, no bairro em que eles vivem, muitas vezes, basta chegar em frente às casas e chamar em voz alta pelo morador. Um dos participantes dessa conversa disse, com certa ironia, sobre fazer visitas em um bairro ou no outro: "lá o difícil é entrar, aqui o difícil é sair [das casas]" (D.C). Comparação carregada de sentidos sobre modos de habitar e de se relacionar com a vizinhança, que se instauram em locais geograficamente próximos, mas muito distantes subjetivamente, causando sensação semelhante à de estar pisando em solo estrangeiro. Efeitos, às vezes despercebidos, da segregação socioespacial urbana. Para além de uma questão do uso do espaço e de acesso a direitos, a segregação representa um distanciamento de mundos em que os modos de vida diferem. Segundo Luis Antonio Baptista (1999), o que ele chama de apartheid gerado pela vida condominizada solidifica e afirma a construção de identidades que moralizam e patologizam o diferente.

Outra situação comum de falta de acessibilidade no local é a dificuldade no uso de aplicativos de transporte, amplamente populares na atualidade. Muitas vezes, as corridas são canceladas 
pelos motoristas quando estes percebem que estão indo para uma vizinhança com características de favela. A moralização desses espaços faz com que esse tipo de localidade, para quem vem de fora, seja excluído dos trajetos possíveis de circulação pela cidade. Como se constituem os mapas mentais no imaginário dos habitantes da cidade é um questionamento que pode encontrar ecos em alguns aspectos da teoria foucaultiana. Em uma entrevista dada em 1982, Foucault (2004a) fala de "paisagens familiares", que se referem a uma organização social à qual estamos habituados, e que são produto de processos históricos bem precisos. A exclusão da população pobre é um processo que acompanha a urbanização desde que as cidades começaram a se expandir ao longo da história. A vida na cidade é regulada por discursos, narrativas dominantes em um determinado espaçotempo. Ao analisar o discurso, examinamse as diferentes maneiras pelas quais ele cumpre uma função dentro de um sistema estratégico de relações de poder. No entanto, as práticas discursivas não são apenas um modo de fabricação desses discursos, mas sim um conjunto de técnicas e procedimentos de transmissão e difusão que fazem o discurso se disseminar, ou capilarizar, no corpo social (Castro, 2009).
Interessava a Foucault analisar "as matrizes normativas de comportamento [...] estudar as técnicas e procedimentos pelos quais se empreende conduzir a conduta dos outros" (Foucault, 2010, p.6). Tomando a cidade como corpo social, há uma série de práticas discursivas atuando no cotidiano, que conduzem os padrões de comportamento da população e que são engendradas pelos próprios habitantes. Essa forma de controle da população faz com que não seja necessária a coerção para manter os corpos em seus lugares determinados; ao contrário, a liberdade é condição de existência das relações de poder (Foucault, 1987). Há a possibilidade de livre circulação na cidade, no entanto, a população tende a manter-se em suas paisagens familiares, modelando seus mapas mentais a partir de certos discursos e perpetuando a segregação existente. Dentre os discursos mais comuns existentes sobre regiões pobres ou favelizadas, está o perigo da criminalidade, tema abordado na segunda unidade de análise, a seguir.

\section{Atmosfera de medo e zonas proibidas}

As regiões mais pobres das cidades são, em geral, associadas à insegurança. A partir dos anos 1980, houve uma expansão da rede internacional de narcotráfico, o que refletiu na ampliação de atividades criminosas relacionadas à venda de drogas 
dentro das comunidades pobres brasileiras, o que gera uma imagem negativa dos moradores desses locais pela associação à criminalidade (Gomes, Fernandes \& França, 2013). O bairro porto-alegrense estudado não foge à regra. Em uma busca por notícias, usando o nome desse bairro em um dos jornais de maior circulação da cidade, dez das onze notícias encontradas (entre os meses de janeiro a julho de 2017) são sobre confrontos e mortes ocorridos no local. Expressões como "assassinado em plena luz do dia", "incendiado", "armas e munições" e "policiamento reforçado" estampam as manchetes do período da inserção em campo. Essa constante veiculação de notícias sobre crimes na região afeta intensamente o cotidiano local, configurando um dos principais tópicos de conversas entre vizinhos. Muitos têm uma história para contar de conhecidos, vizinhos ou parentes que foram vítimas da violência local. Essas histórias percorrem o território, assumindo caráter quase mítico e adensam a atmosfera de medo e ansiedade.

Além do medo incitado pela mídia, a população também convive com locais "proibidos", definidos pelas zonas de domínio do tráfico. Uma moradora explicou que não pode circular em determinada área do bairro por ser uma pessoa bastante conhecida no local onde mora, cujo domínio é exercido por um grupo de tráfico rival ao que domina a outra área. Segundo ela, ser vista andando na área do outro grupo pode gerar desconfiança dos chefes do tráfico. Ao contar seu cotidiano, fica evidente que ela precisa planejar suas rotas diárias levando essas questões em conta. Essa não é necessariamente a realidade de todos os moradores, mas ao conversar sobre o tema com a população local, esse tipo de situação não causa estranhamento, já é algo naturalizado. Dentro do bairro, essas demarcações de diferenças entre uma vizinhança e outra são comuns: muitas vezes, ao dobrar da esquina, as regras mudam. Esse problema parece se agravar ainda mais no caso de homens jovens e negros, que por vezes têm seus caminhos interrompidos por abordagens das lideranças do tráfico, que precisam se certificar que não estão sendo espionados por rivais ou policiais à paisana.

Os líderes do tráfico eram descritos como meninos bem jovens, adolescentes, e, por isso mesmo, muito agressivos quanto mais jovens, mais é preciso fazer uso da violência para serem respeitados e assumirem um status mais elevado. "Eles precisam mostrar poder" (D.C.), contou uma moradora. Mas que tipo de poder é esse que precisa ser mostrado por esses sujeitos que atuam de maneira tão contundente no território? É importante 
delimitar que o poder não é um atributo do qual a pessoa possa se apoderar, tomar posse, pois não é "algo em si” e sim uma “operação" (Passos, 2013). Assumindo essa lógica, talvez a pergunta correta não seria "que poder é esse", mas o "como" desse poder, ou seja, quais as condições que tornam possíveis esse tipo de relação de poder entre moradores e líderes do tráfico dentro da comunidade.

Os moradores da região estudada, ao primeiro olhar, parecem viver à mercê do domínio dessas lideranças, que usam da força e da coerção para delimitar seus espaços. Essa questão se destaca como um verdadeiro entrave de mobilidade, levando as pessoas a modificarem suas rotas, evitarem possíveis atalhos para irem de um local ao outro e, no limite, deixarem de circular na rua, em especial em horários noturnos ou em períodos específicos em que há "toque de recolher". Mas ao mesmo tempo, ouvem-se comentários como:

Eu não convivo [com o crime], não concordo com isso, mas só quem mora em comunidades como a nossa aprende uma coisa: é cada um no seu quadrado (Cazuza).

Eu conheço bem a linguagem da vila. A periferia tem um código interno de condutas que quem é de dentro conhece [...] assim como eu respeito, eu exijo meu respeito (Anita)

Se cada um faz a sua parte, levanta cedo para o serviço, sai e volta, eu acho que é tranquilo [viver no bairro, apesar da presença do tráfico] (Joana).

Pode-se perceber que as queixas em relação à criminalidade são recorrentes nas conversas cotidianas, mas há também relativizações, como se vê na fala dos entrevistados. Algumas vizinhanças parecem ter pactos mais bem estabelecidos de respeito mútuo e, em outras, o pavor de retaliações injustas é uma realidade. Segundo Feltran (2016b),

Esse mundo do crime, entretanto, não domina os territórios ou as populações tiranicamente. A posse das armas e a disposição para utiliza-las é, evidentemente, a fonte última da legitimidade e autoridade [...]. Entretanto, cotidianamente, esses grupos manejam componentes muito mais sutis de disputa pelas normas de convivência [...] não se trata de um jugo ou de uma dominação autoritária, tampouco trata-se de um movimento democrático: a questão é que o crime emerge noutra chave de compreensão, como resultante de trocas sociais complexas [...] obtendo dessas trocas consentimentos ativos e legitimidade para ali se estabelecer (Feltran, 2016b, p.57-58).

Essas trocas e consentimentos podem ser percebidas ao lançar-se um olhar aprofundado para a região, que adota um modo de funcionamento particular, naturalizando alguns processos locais de 
dominação. Tanto o domínio do tráfico em si, quanto o medo da violência operada por esses grupos, são barreiras invisíveis de mobilidade, pois dificultam uma circulação fluida dos habitantes, que poderiam se beneficiar do uso mais despreocupado dos espaços urbanos locais. Os ideais de saúde incentivados pela Organização Mundial da Saúde, inclusive nas discussões sobre Saúde Urbana, parecem distantes quando se percebe que alguns problemas vão muito além de questões estruturais como melhorias urbanísticas, incremento de áreas verdes, entre outros. Por essa razão, observar as particularidades locais é considerado essencial, inclusive pela própria Organização. A próxima unidade de análise segue mostrando outras relações sociais singulares percebidas na área estudada.

\section{Muros grossos e paredes finas}

A entrevistada Anita percebe a região de forma especial, pois adquiriu uma casa no local depois ter vivido em outro bairro, onde havia ocupado sua área de moradia. De repente, viu-se assumindo outra posição social no novo bairro, onde chegava com o status de proprietária. Sentindo-se um pouco parte dos dois mundos, ela tenta driblar a segregação entre grupos em conflito, denominados por ela como “os proprietários” e “os ocupantes". O condomínio de Anita tem características atípicas em relação à maior parte dos condomínios atuais, pois o conjunto de casas não está isolado por muros. Um loteamento para população de classe média trabalhadora do comércio, construído nos anos 1960, transformou-se nesse condomínio, mudando de nome e ganhando regimento próprio. Mesmo sem estar concretamente separado do seu entorno, o condomínio estabelece barreiras invisíveis que tornam possível uma vida segregada. Anita relata que há uma constante "irritação" dos moradores do condomínio causada pela passagem dos moradores das "vilas" próximas (referindose às áreas favelizadas). Uma das "vilas" à qual Anita se refere caracteriza-se por um aglomerado de casas construídas na subida localizada logo atrás de sua rua, que poderia ser descrita como uma típica via de assentamento informal.

As diferenças causadas pela "informalidade" se traduzem, principalmente, na ausência de sinalização e calçamento, que pode causar estranhamento a quem está habituado a uma concepção hegemônica de urbanidade. Para os habitantes do local, no entanto, a aparente falta de regras está normalizada nos modos de transitar, ou seja, não parece constituir obstáculo de mobilidade. Andando com destreza nas 
vias que percorrem diariamente, os moradores encontram vizinhos e criam espaços de convivência (como cadeiras de praia em frente às casas) e lazer (jogar bola no meio da rua, por exemplo). É possível, no entanto, que as normas instituídas fora dali, na "cidade formal" (como Anita se refere às partes da cidade onde não há presença de favela), possam servir como barreiras invisíveis, inibindo o uso desses outros espaços pela população do assentamento informal. Há também nesses locais uma maior exposição do interior das casas, com uma delimitação menos óbvia entre fora e dentro, casa de um e casa de outro, já que muitos terrenos são divididos por vários núcleos de uma mesma família ou por famílias diferentes - particularidade que inspirou a analogia "paredes finas". Raquel Rolnik resgata as origens da intimização dos lares a partir do final do Século XIX, ligada a um movimento da burguesia de reorganização do espaço de moradia. "O lar - domínio de vida privada do núcleo familiar e de sua vida social exclusiva - se organiza sob a égide da intimidade. [...] a vida social da burguesia se retira da rua para se organizar à parte, em um meio homogêneo de famílias iguais a ela" (Rolnik, 1994, p. 27).

As "paredes finas", ou seja, essas relações estreitadas e permeáveis entre os "ocupantes" contrastam com as formas de se relacionar dos "proprietários": "Os moradores [do condomínio] investem nas suas próprias casas, deixando bonitas e agradáveis, mas não investem na convivência" (Anita). Essas desconexões e distâncias se estabelecem em um espaço mesclado, onde não existem muros de separação entre um grupo e outro, mas a segregação e diferenciação acontecem por outras vias. Desde as cidades coloniais brasileiras, as distâncias entre grupos sociais que estão próximos fisicamente podem ser expressas por modos de vestir, gestualidades, atitudes e, inclusive, traços étnicos como o tom da pele (Rolnik, 1994). Há nessas estratégias uma forma de contenção (disciplinamento de si) e dominação (disciplinamento do outro): cria-se um modelo de comportamento, ou de normalidade, que se não é seguido, coloca o sujeito na condição de incivilizado (Fou cault, 2008b).

"Eles dizem: se eu comprei a minha casa com todas as dificuldades, porque eu tenho que conviver com esses marginais?" (Anita). Há um tom de disputa sobre quem tem mais direito a habitar o bairro, que perpassa a questão da propriedade. O termo "marginal" utilizado carrega o peso dessa categorização que põe esse grupo na condição de "outro", não pertencente a uma certa organização social. Essas diferenciações constituem barreiras "invisíveis" de mobilidade tanto para os "proprietários", que podem inibir sua 
própria circulação para não se expor à alteridade, quanto para os "ocupantes", que podem não se sentir à vontade circulando nas áreas próximas aos condomínios, onde os códigos de conduta contrastam com seus modos próprios de utilização do espaço. Dessa forma, "proprietários" se isolam, procurando proteção atrás dos muros de suas casas, enquanto "ocupantes" limitam sua utilização do espaço público apenas dentro do seu pequeno núcleo comunitário (beco ou viela).

Apesar disso, durante o curso da pesquisa, foi possível perceber que, em alguns casos, as pessoas "extravasam" essas barreiras e buscam formas inventivas de afirmar sua presença nos espaços do território local ou da cidade. Essas chamadas "rotas alternativas" compuseram a última unidade de análise.

\section{Pontes e rotas alternativas}

Como muitas pessoas de sua geração, Mogli, aos 22 anos, representa bem a época em que vivemos, onde cada vez mais pessoas desassociam seus modos de ser dos laços territoriais. A globalização produz uma crescente internacionalização de grupos unidos por ideias, hábitos e ideologias - e o cicloativismo, movimento que passou a ganhar mais visibilidade no Brasil nos anos 1990 (Soares, 2014) e ganhou muitos adeptos com o passar das últimas décadas, pode ser considerada uma comunidade com características de tribo urbana. No caso de Mogli, a utilização da bicicleta representa uma noção de comunidade mais intensa do que a pertença ao seu bairro de origem. Longe de ser apenas um meio de transporte, ela lhe proporcionou novas experiências de socialização:

A comunidade ciclista é muito fácil de conhecer, eles são muito receptivos, porque tu chegas a algum lugar de bicicleta e já vem alguém conversar contigo. Isso já cria um vínculo, talvez a conversa não seja longa, mas tu acabas conhecendo as pessoas. Tem eventos todo o mês, onde eu conheci muita gente [...] tenho grandes amigos que conheci na comunidade ciclista (Mogli).

Embora, por certo, seus laços territoriais com a comunidade de origem não deixem de constituí-lo, o ciclismo parece ter ampliado a "esfera de pertencimento" (Lyra, 2016) de Mogli, assim como seus espaços de circulação pela cidade. Poderíamos pensar que a bicicleta como meio de transporte foi um dos fatores que impulsionaram a construção de "pontes" para atravessar o "abismo" mencionado na primeira unidade de análise. A partir dela, Mogli conquistou novos espaços na cidade e diminuiu a sensação de isolamento provocada pelo seu contexto de moradia. O cicloativismo tem sido associado com outros ativismos relacionados a estilos de vida mais 
sustentáveis e é interessante perceber como esses valores vêm se disseminando, especialmente, entre jovens, a partir das mídias contemporâneas, mesmo que o acesso a esses conteúdos também não ocorra de forma democrática entre os diferentes contextos econômicos. Houve, para Mogli, uma via de acesso a outro modo de vida a partir de experiências relacionadas com sua escolha de meio de transporte. Pelo seu relato, é possível perceber que os benefícios obtidos através da mobilidade ativa são muito mais complexos do que a melhora da condição física e do nível de bem-estar proporcionado pelo exercício, por exemplo. Há uma expansão de possibilidades de subjetivação obtida ao acessar novos espaços da cidade, locomovendo-se com esse modal específico. Sob a ótica foucaultiana, as experiências de Mogli com a bicicleta proporcionaram movimentos inéditos que produziram diferenciações éticas (Foucault, 2004b), importantes para a sua constituição enquanto sujeito.

Mas também é possível reconhecer muitas outras maneiras de construir "pontes", e a história dos outros participantes demonstra que permanecer no território e fortalecer conexões locais também pode ser vista como uma forma de resistência. Anita manifesta seu encanto pelo bairro que escolheu morar. O que às vezes é sentido como "ilha" também tem seu aspecto de "oásis". Do alto do morro, ela se sente privilegiada pela vista que tem da cidade em todos seus contrastes "a cidade formal $[\ldots]$ o verde da natureza $[\ldots]$ a ocupação das casinhas, a favela" (Anita). Sua história de vida não a deixa perder o olhar crítico sobre as questões comunitárias, nem se deixar vencer pela polarização entre "proprietários" e "ocupantes". Em um ato simbólico, convidou um morador da "vila" ao lado para fazer um grafite no muro de casa, retratando a vista que vê da sua janela. Assim, deu outra função, mais interativa, à barreira existente entre o espaço privado e o público, compartilhando uma vista que é só dela com os transeuntes.

Cazuza e Joana se orgulham de ter visto o bairro crescer e de terem dedicado parte de suas vidas a esse processo de construção, a partir da organização comunitária, hoje sentida como enfraquecida. Cazuza ainda resiste, ocupando a liderança de uma das associações de moradores locais. Talvez ter a própria existência tão ligada ao local de moradia seja uma forma de resistência em um mundo onde impera o enfraquecimento dos laços territoriais e um clamor pelo consumo de modos de vida globalizados, hegemônicos. Não se deixar dissolver no contexto contemporâneo, a partir do exercício de práticas do comum (no sentido de vida em comum, compartilhada), pode ser uma forma de empreender a resistência e tensionar a atual lógica neoliberal individualizante: 
Resistir é a capacidade que a força tem de entrar em relações não calculadas pelas estratégias que vigoram no campo político. A capacidade que a vida tem de resistir a um poder que quer geri-la é inseparável da possibilidade de composição e de mudança que ela pode alcançar. Resistir é, neste aspecto, o oposto de reagir. Quando reagimos damos a resposta àquilo que o poder quer de nós; mas quando resistimos criamos possibilidades de existência a partir de composições de forças inéditas. Resistir é, neste aspecto, sinônimo de criar (Maciel Junior, 2014, p. 2).

\section{Considerações finais}

Em síntese, os "achados" desse estudo trazem à tona os principais elementos subjetivos que afetam a mobilidade urbana saudável da população da região estudada e, possivelmente, de outras regiões semelhantes na cidade de Porto Alegre ou de outras cidades brasileiras. Cada um desses elementos nos dá indícios das relações de poder engendradas no espaço urbano, que se atualizam nos modos de subjetivação da sociedade contemporânea.

A primeira barreira invisível foi chamada de "abismo", que diz respeito ao isolamento simbólico da região estudada em relação ao resto da cidade. Ela se faz presente, em especial, na maneira como é organizada a oferta de transporte público no local e nas falas dos moradores que denunciam uma sensação de estar à parte da cidade, ilhados. Atuando em conjunto com isso, está outra barreira importante: a "atmosfera de medo". O clima de insegurança acentua a segregação socioespacial ao inibir a circulação de quem é de fora do território, assim como também desestimula os moradores a usufruírem do espaço público das vizinhanças. Essa barreira, em específico, tem suas estruturas reforçadas diariamente através da mídia, que fabrica discursos reproduzidos por grande parte da população de Porto Alegre.

Além da atmosfera reforçada pelos discursos, existem locais perigosos, chamados aqui de "zonas proibidas". São os espaços dominados por grupos de tráfico, que regulam a passagem dos moradores. É complexo pensar em mobilidade saudável em um local onde a população precisa levar em conta um obstáculo desse tipo em seus trajetos diários. Ir a pé de um lugar ao outro pode, por um lado, ser a opção mais benéfica para a saúde e, por outro, ser a que deixa o indivíduo mais vulnerável aos riscos do ambiente. Para entender melhor como se constituem essas barreiras no cotidiano da comunidade, foi preciso analisar algumas 
das complexas e múltiplas relações de poder existentes.

Da observação das dinâmicas sociais do território, sobressaiu-se outra barreira invisível muito presente: as disputas de espaço entre os "ocupantes" e os "proprietários". Essa barreira, em especial, mostra como há uma complexa trama que movimenta os circuitos da vida dos moradores, que se diferenciam entre si, se excluem e se incluem, aos seus próprios modos. Entender como funcionam esses processos ajuda a conhecer os múltiplos meios de produzir segregação socioespacial.

O último elemento não é uma barreira, ao contrário, são as invenções criadas para superar as distâncias e muros simbólicos construídos. Parece que a principal solução para a imobilidade urbana local não está na tentativa de demolir barreiras, mas na construção de novos caminhos, ou rotas alternativas. Cada entrevistado mostrou como, do seu jeito, executou um trabalho ético para buscar uma existência saudável (saúde como qualificação da existência) na comunidade e/ou na cidade como um todo.

Defende-se, por fim, que, ao perceber mais profundamente a realidade, nos deparamos com o fato de que muitas das amarras que nos imobilizam são construções sociais, e, por isso mesmo, mutáveis. Conhecer diferentes formas de existência na cidade - ao ouvir e registrar a história de sujeitos subjetivados em outros contextos urbanos - pode acrescentar ferramentas para desconstruirmos alguns dos regimes de verdade vigentes.

\section{Referências}

Andrade, A., Morato, H., \& Schmidt, M. (2007). Pesquisa interventiva em instituição: etnografia, cartografia e genealogia. In $\mathrm{M}$. Rodrigues \& P. Menandro, Lógicas metodológicas: trajetos de pesquisa em psicologia (pp. 193-206). Vitória: Editora GM.

Baptista, L. (1999). A cidade dos sábios. São Paulo: Summus.

Cardoso Filho, C. A. (2016). A subjetividade, o fora e a cidade: repensando o sujeito, o espaço e a materialidade. Fractal: Revista de Psicologia, 28(2), 242-251. https://doi.org/10.1590/1984$\underline{0292 / 1458}$

Carvalho, C. (2016). Mobilidade Urbana: avanços, desafios e perspectivas. Em M. Costa, $O$ Estatuto da Cidade e a Habitat III: um balanço de quinze anos da política urbana no Brasil e a Nova Agenda Urbana (pp. 345-361). Brasília: IPEA.

Castro, E. (2009). Vocabulário de Foucault. Belo Horizonte: Autêntica. 
Cohen, J., Boniface, S., Watkins, S. (2014). Health implications of transport planning, development and operations. Journal of Transport and Health. 1, 63-72. https://doi.org/10.1016/j.jth.2013.1 $\underline{2.004}$

Denzin, N., Lincoln, Y., \& Netz, S. (2006). $O$ planejamento da pesquisa qualitativa(2nd ed.). Porto Alegre, RS: Artmed.

Domingues, Á. (1994). (Sub)úrbios e (sub)urbanos: o mal estar da periferia ou a mistificação dos conceitos. Revista da Faculdade de Letras: Geografia, X(XI), 5-18. Recuperado de https://ojs.letras.up.pt/index.php/ge ografia/article/viewFile/7777/7135

Feltran, F. (2016a). A Lei de Mobilidade Urbana como instrumento de efetivação do direito à cidade e à inclusão social. Âmbito Jurídico, $\quad$ XIX(147), 1-4. Recuperado de https://ambitojuridico.com.br/site/?n_link=revista _artigos_leitura\&artigo_id=17044

Feltran, G. (2016b). Transformações sociais e políticas nas periferias de São Paulo. In R. Rolnik \& A. Fernandes, Cidades (pp. 41-67). Rio de Janeiro: Funarte.
Ferigato, S., \& Carvalho, S. (2011). Pesquisa qualitativa, cartografia e saúde: conexões. Interface, 15(38), 663-676.

https://doi.org/10.1590/S1414$\underline{32832011005000037}$

Flick, U. (2009). Introdução à pesquisa qualitativa (3rd ed.). Porto Alegre: Artmed.

Foucault, M. (1979). O nascimento da medicina social. In $M$. Foucault, Microfísica do poder (pp. 79-98). Rio de Janeiro: Edições Graal.

Foucault, M. (1987). Vigiar e punir: nascimento da prisão (5th ed.). Petropolis: Vozes.

Foucault, M. (2004a). Verdade, poder e si mesmo. In M. Foucault, Ética, sexualidade, política: Ditos e escritos V(pp. 294-300). Rio de Janeiro: Forense Universitária.

Foucault, M. (2004b). A ética do cuidado de si como prática da liberdade. In: In M. Foucault, Ética, sexualidade, política: Ditos e escritos $V$ (pp. 264-287). Rio de Janeiro: Forense Universitária.

Foucault, M. (2008a). História da loucura na Idade Clássica. São Paulo: Editora Perspectiva. 
Foucault, M. (2008b). Segurança, território e população: Curso dado no Cóllege de France (1977-1978). São Paulo: Martins Fontes.

Foucault, M. (2010). O governo de si e dos outros: curso no Cóllege de France (1982-1983). São Paulo: Editora WMF.

HUM Project. (2016). Mobilidade Urbana Saudável: Contexto. Acesso em 23 Outubro 2017, Recuperado de https://www.hummus.org/pt/sobre/contexto/

IBGE. (2018). Censo 2010: Aglomerados subnormais informações territoriais. Brasília, DF, Brasil. Acesso em 5 de Maio de 2018. Recuperado de https://ww2.ibge.gov.br/home/presi dencia/noticias/imprensa/ppts/0000 0015164811202013480105748802 . pdf

Justo, J. S., Heguedush, C. V. (2019). Cidade e racionalização da subjetividade: implicações das ciências da saúde e educação. Rev. Polis e Psique, 9(2), 87-111. https://doi.org/10.22456/2238152X.87518

Lyra, D. (2016). Cartografias afetivas na cidade: as esferas de pertencimento de jovens traficantes da Baixada Fluminense. In R. Rolnik \& A. Fernandes, Cidades (pp. 149-166). Rio de Janeiro: Funarte.
Maciel Junior, A. (2014). Resistência e prática de si em Foucault. Trivium, 6(1), 1-8. Recuperado de http://pepsic.bvsalud.org/pdf/triviu $\underline{\mathrm{m} / \mathrm{v} 6 \mathrm{n} 1 / \mathrm{v} 6 \mathrm{n} 1 \mathrm{a} 02 . p d f}$

Passos, I. (2013). Situando a analítica do poder em Michel Foucault. In I. Passos, Poder, normalização $e$ violência: incursões foucaultianas para a atualidade (pp. 7-19). Belo Horizonte: Autêntica Editora.

Paulon, S. (2005). A análise de implicação com ferramenta na pesquisa-intervenção. Psicologia \& Sociedade, 17(3), $18-25$. https://doi.org/10.1590/S010271822005000300003

Rolnik, R. (1994). O que é cidade. São Paulo: Editora Brasiliense.

Soares, A. G. (2014) Os desafios da formalização do cicloativismo em nível nacional. In: J. C. A. Belloto et al (Org.). A cidade em equilíbrio: contribuições teóricas ao $3^{\circ}$ fórum mundial da bicicleta. Curitiba: Proec/UFPR, 200-206.

World Health Organization, \&. U.-H. (2016). Global Report on Urban Health: equitable, healthier cities for sustainable development. Geneva: WHO. Recuperado de https://apps.who.int/iris/handle/106 $\underline{65 / 204715}$ 
Luísa Horn de Castro Silveira é

Doutoranda em Psicologia Social e

Institucional pela UFRGS e Mestra em

Saúde Coletiva pela mesma instituição.

E-mail: luisahsilveira@gmail.com

ORCID:https://orcid.org/0000-0001-6706-

$\underline{922 X}$

Cristianne Maria Famer Rocha é

Doutora em Educação e Professora

Associada da Escola de Enfermagem da

UFRGS.

E-mail: cristianne.rocha@ufrgs.br

ORCID:http://orcid.org/0000-0003-3281-

$\underline{2911}$

Julio Celso Borello Vargas é Doutor em Engenharia de Transportes e Professor Adjunto do Departamento de Urbanismo e do Programa de Pós-graduação em Planejamento Urbano e Regional da UFRGS.

E-mail: julio.celso@ufrgs.br

ORCID:https://orcid.org/0000-0001-8321$\underline{5362}$

Enviado em: 30/01/20- Aceito em: 20/10/20 